United States Department of Agriculture

Agricultural Research Administration

Bureau of Entomology and Plant Quarantine

\title{
THRESHER AND SEPARATOR FOR RED CLOVER SEED SAMPLES
}

By A. W. Woodrow, Division of Bee Culture,

and B. A. App, Division of Cereal and Forage Insect Investigations $1 /$

The red clover head consists of about 100 florets, each of which must be cross-pollinated to produce one seed. Consequently, to evaluate correctly the activity of pollinating insects, it is essential to save all seeds, including poorly developed, lightweight ones, which are ordinarily lost in threshing. Imperfect seeds must be taken into account also in determining the insect damage to the clover and in appraising the effectiveness of insecticide treatments. Because of the small size of the seed it is difficult to thresh the clover without loss. Hand threshing is effective, but it is a time-consuming, dusty, and otherwise unpleasant task. Therefore, small machines were developed for threshing and separating this seed.

\section{Seed Thresher $\underline{2}$}

The thresher, pictured in figure 1 and diagrammed in figure 2, consists of two functional parts, a cylinder (A) and a stationary apron or belt ( $(\underline{B})$ against which it revolves. The cylinder is made by mounting a section of 9 -inch, 24-gage, galvanized-iron furnace pipe 8 inches long on wooden disks turned out of $7 / 8$-inch lumber. It is covered with corrugated rubber (C) such as is commonly used for stair treads or hall runners. This material is about $1 / 8$ inch thick with eight corrugations, $1 / 16$ inch deep, per inch. It is cemented to the cylinder with reclaimedrubber resin-base cement, the corrugations extending lengthwise in a

1/ In cooperation with the Ohio State University and the Ohio Agricultural Experiment Station, and with the Bureau of Plant Industry, Soils, and Agricultural Engineering.

2/ The authors are indebted to R. D. Barden, Department of Agricultural Engineering, Ohio State University, for advice in planning the construction of this thresher. 


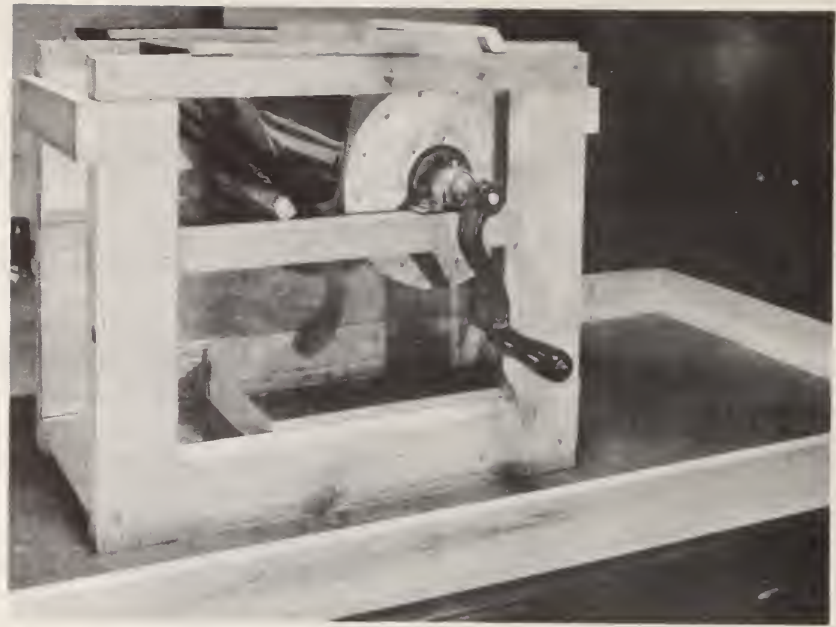

Figure 1.--Clover seed thresher. Sheet-metal liner has been removed from side in foreground.

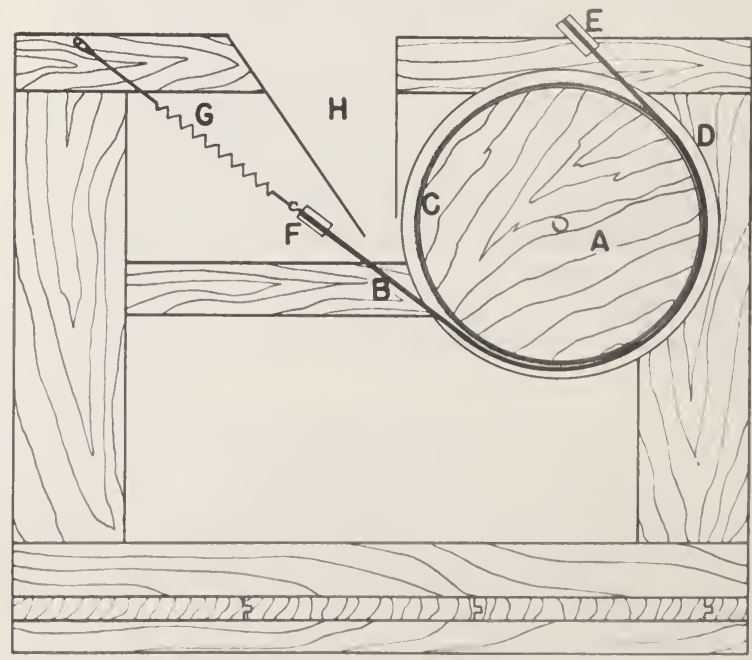

Figure 2. --Sectional diagram of clover seed thresher. 
slightly diagonal direction. A galvanized-iron disk (D) about 10 inches in diameter is fastened to each end of the cylinder to hold the belt in position against the cylinder. Flanged set collars attach the cylinder to a $1 / 2$-inch shaft mounted at each end in self-aligning bronze bushed pillow blocks. Set collars to maintain the position of the cylinder and a hand crank mounted on the end of the shaft complete the assembly.

The belt $B$ is made from a piece of sponge-rubber rug anchor, about $1 / 16$ by $71 / 2$ by 24 inches, cemented to fly screening of the same dimensions. A piece of 16- by 16-mesh aluminum fly screen without a covering is fairly satisfactory but less so than the rubber-surfaced belt because it sometimes becomes clogged with stems.

The belt girds approximately half of the cylinder like a power belt around a pulley, but it does not move with the cylinder. It is held in place at each end by clamps ( $E$ and $F$ ) made of wood or wood and strap steel. The end of the belt at $\bar{E}$ is held stationary, and the other end is attached to the frame by a coil spring (G) at each side. This arrangement gives flexibility to the belt when clover heads are poured in for threshing through the chute $(\underline{H})$, which is made of sheet metal.

When the machine is viewed as in figures 1 and 2, the cylinder is turned counterclockwise to roll and rub clover heads against the belt. Since each floret must be ruptured to release the seed, the chaff is almost completely pulverized, some of it being carried completely around by the revolving cylinder. As the partially pulverized chaff containing the seed is taken from the thresher, it is passed through a 12 - by 12-inesh screen and the screenings are returned to the thresher. When all florets are ruptured, the material is passed through the separator (figs. 3 and 4 ) to remove the chaff.

The sides and floor of the thresher are lined with sheet metal, and baffles are used on the ends to prevent seeds from being thrown out and lost. As a further precaution, the thresher is set in a tray, about 28 by 60 inches with sides 3 inches high, which catches seeds that may be spilled. The belt is detached when the machine is emptied, and all seeds can be removed before another lot is processed.

\section{Seed Separator}

The seed separator, or cleaner, shown in figures 3 and 4 , employs the air stream of an exhaust fan instead of the usual blower-fan air blast to separate seed and remove chaff. An old household fan-type vacuum cleaner is used, arranged so that the air stream may be adjusted. All separation fractions removed from the seed may be caught by a screen and examined. The dusty chaff may be caught in the cleaner bag instead of being blown about the laboratory.

Wooden parts are made of 3/4-inch poplar. Both ends are held in place with small metal buttons so they can be removed easily for cleaning the main box. 

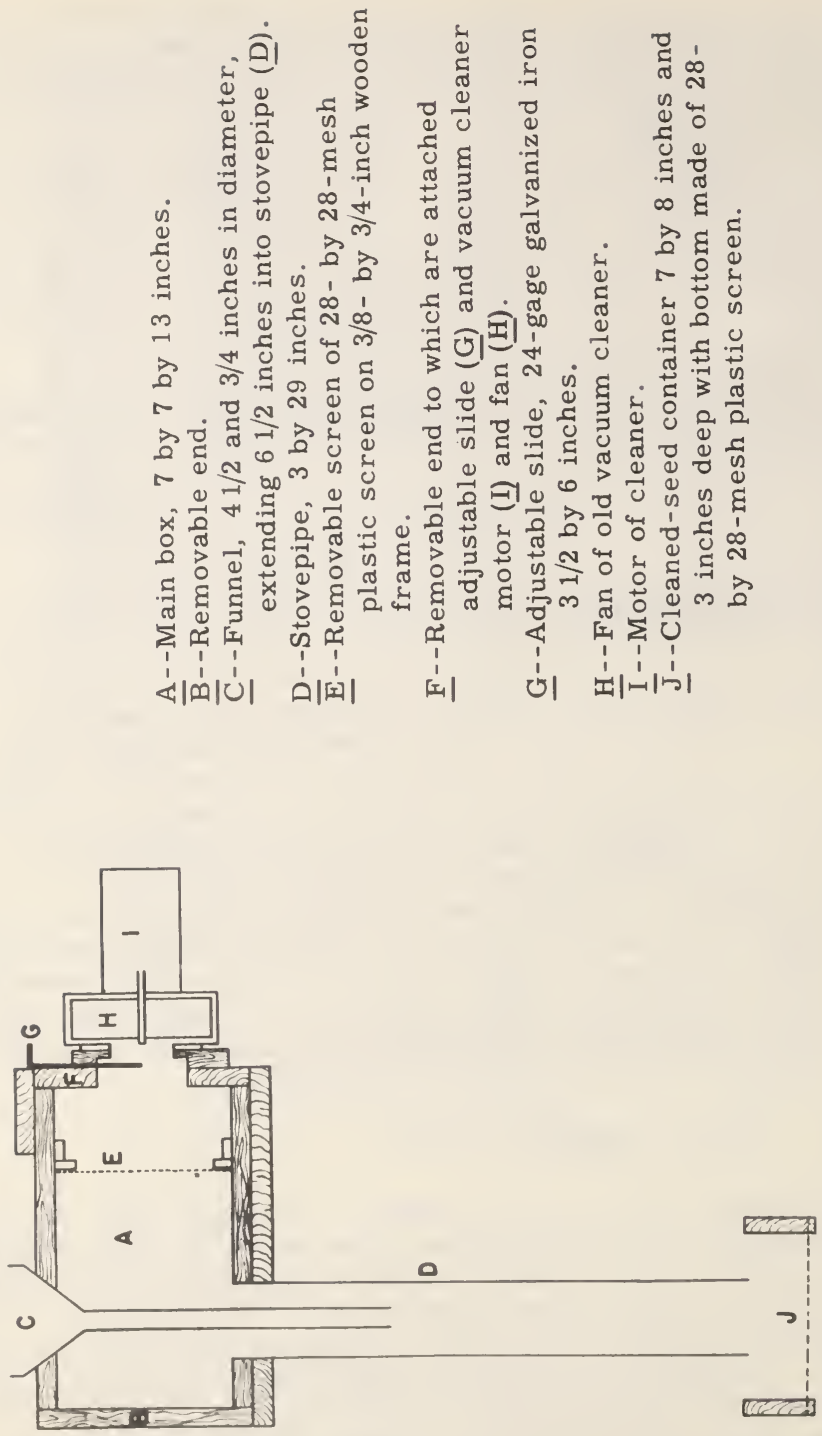


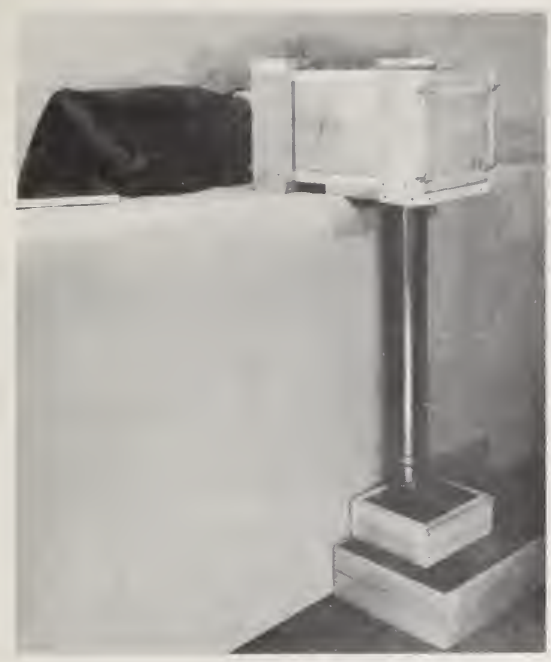

Figure 4.--Clover seed separator.
The chaff containing the seed as taken from the thresher is poured through the funnel $\underline{C}$ into the air stream in the stovepipe

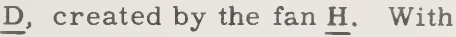
properly adjusted velocity of air the seed falls through the stovepipe into the cleaned-seed container $\mathrm{J}$ underneath, while the chaff is carried by the air stream into the box $\underline{A}$. In $\underline{A}$ the reduced velocity allows the heavier materials to drop while the lighter, dusty portion passes through the fan $\mathrm{H}$ into the cleaner bag. With the removable screen $E$ in place, all material removed from the seed except the finest chaff may be caught in $A$, where it may be examined. Air velocity is controlled by adjustment of slide $\underline{G}$, which serves as a

damper to change the size of the inlet opening to the fan. For convenience the slide is calibrated arbitrarily according to the diameter of the opening, from 0 to 5 . The setting of 5 gives the minimum practical operating opening of about 10 percent, and at the setting of 0 the inlet is completely open. With the slide at position 5 all the fine dusty chaff is carried into the bag and few, if any, seeds are removed. With the opening at position 4 most of the coarse and heavy chaff is removed along with some of the lighter seeds. The 3 setting, which increases the opening to the fan to about 50 percent, removes the remainder of the chaff and practically all the light seeds. Further separations may be made at the 2, 1, and 0 settings if desired, but these remove more good seed.

The separator is very efficient in separating the seed and cleaning out the refuse. Large pieces of stems are not easily handled, however, and they should be removed by screens. Light seeds and stems are usually carried out together, and some hand separations may be necessary if detailed examinations of these seeds are required. Accumulated dust in the bag creates air resistance and reduces the velocity of the air stream in the separator. Samples obtained by plucking only the clover heads in harvesting are handled mora efficiently by the separator, and also by the thresher, than are those that include the stems and leaves also.

The results obtained when 2 samples of red clover totaling 91 heads and containing 80 percent of good seeds were threshed and passed through the separator 6 times, once at each slide setting, are given in table 1 . 
Table 1.--Separation of red clover seed passed through separator at various slide settings.

\begin{tabular}{|c|c|c|c|c|c|}
\hline \multirow[t]{2}{*}{$\begin{array}{c}\text { Slide } \\
\text { setting } \\
\text { No. }\end{array}$} & \multirow[t]{2}{*}{$\begin{array}{l}\text { Percent of } \\
\text { total open- } \\
\text { ing to fan }\end{array}$} & \multirow[t]{2}{*}{$\begin{array}{c}\text { Total number } \\
\text { of cleaned } \\
\text { seeds }\end{array}$} & \multicolumn{2}{|c|}{$\begin{array}{l}\text { Percent of } \\
\text { original seeds } \\
\text { found in refuse }\end{array}$} & \multirow[t]{2}{*}{ Remarks } \\
\hline & & & Good & Poor & \\
\hline 5 & 10 & 4,101 & 0 & 0 & All fine chaff removed \\
\hline 4 & 29 & 3,830 & .3 & 33 & $\begin{array}{l}\text { Some coarse chaff } \\
\text { remained }\end{array}$ \\
\hline 3 & 50 & 3,451 & .7 & 76 & $\begin{array}{l}\text { Practically all chaff } \\
\text { removed }\end{array}$ \\
\hline 2 & 71 & 2,945 & 11 & 94 & All chaff removed \\
\hline 1 & 89 & 2,124 & 36 & 98 & \\
\hline 0 & 100 & 1,759 & 46 & 100 & $\begin{array}{l}\text { All small seeds } \\
\text { removed }\end{array}$ \\
\hline
\end{tabular}

In each separation of these samples, except at the minimum slide setting of 5 , some seed was carried over in the chaff. The quantity increased with the air velocity until at maximum velocity all the poor seeds and nearly half of the good seeds were carried over. At the 3 setting 76 percent of the poor seeds were removed; 94 percent of the cleaned seed was good, but because of the small size and light weight of the poor seeds, they made up only 4 percent of the weight of the cleaned seed. Although a setting of 2 reduced the number of poor seeds to only 2 percent, it removed 11 percent of the good seeds.

Because of variations in weight of seed, it is to be expected that results will vary from those given for these two samples. In actual use, the 5 setting is used to remove the dust and then the 3 setting with the screen in place is used to finish the cleaning. Samples of about 1 gram each of cleaned seed and of refuse are then examined under a microscope for the evaluation of pollination resulting in small seeds and of insect damage, as well as other factors. Seeds damaged by the clover seed chalcid (Bruchophagus gibbus (Boh.)) are easily separated with the 3 setting, but many seeds of this type are crushed in threshing and cannot be identified. 